\title{
Fratura radicular horizontal com cicatrização espontânea: relato de caso
}

\author{
Spontaneously healed horizontal root fracture: a case report \\ Fractura radicular horizontal con cicatrización espontánea: reporte de caso
}

\section{Resumo}

A fratura radicular horizontal pode ser definida como aquela que envolve dentina, cemento, ligamento periodontal e polpa, compreendendo de 1,2 a $7 \%$ dos traumas na dentição permanente. Afeta normalmente a região de dentes anteriores, e geralmente cicatriza-se espontaneamente, dependendo da vitalidade pulpar. O diagnóstico é realizado através de exame clínico, teste de sensibilidade pulpar e exame radiográfico. Além disso, a Tomografia Computadorizada de Feixe Cônico tem sido utilizada de forma a auxiliar no diagnóstico e prognóstico, devido a reprodução de imagens tridimensionais, permitindo visualizar de forma exata a localização e trajeto da linha de fratura. Este estudo relata um caso clínico de trauma dental causado por queda de própria altura. A paciente apresentava fratura radicular horizontal no elemento 21, localizada em terço médio, que foi confirmada através do exame radiográfico. Como tratamento imediato, foi realizado o reposicionamento e esplintagem. Para a confirmação da localização exata da fratura e se houve o processo de cicatrização, foi realizada imagens de tomografia computadorizada de feixe cônico após 30 dias do trauma, pôde-se visualizar a fratura com trajeto oblíquo cicatrizada por tecido calcificado. Dessa forma, optou-se por acompanhamento da fratura radicular horizontal com tempo de controle de 15 dias, 30 dias, 60 dias, 2 anos e 5 anos. Permitindo, assim, que o dente seja preservado na cavidade bucal, sem intervenções.

Palavras-chave: Endodontia regenerativa; Traumatismo Dentário; Prognóstico; Cicatrização; Tomografia Computadorizada de Feixe Cônico.

\footnotetext{
Abstract

Root fractures are defined as those that involve cement, dentin and pulp, comprising from 1,2 to $7 \%$ of injuries in permanent dentition. Usually affects the maxillary anterior region, and generally heals spontaneously, depeding on the vitality of the pulp. Diagnosis is made by clinical findings, sensitivity tests and radiographic examination. Futhermore, cone-beam computed tomography (CBCT) has been used for diagnosis and prognosis, due to the reproduction of three-dimensional images, the location and the path of the fracture line can be accurately visualized. This study reports a case of dental trauma caused by fall from own height. The patient suffered horizontal root fracture in maxillary left central incisor, wich was confirmed from radiographic examination, positioned at the end of the middle third. As immediate treatment, it was performed the repositioning and spliting. To confirm the exact location of the fracture and if healing occurred, CT images of the were performed 30 days after the trauma and the fracture with an oblique path healed by calcified tissue could be visualized. In this way, it was decided to follow-up the horizontal radicular fracture with the control time of:15 days, 30 days, 60 days, 2 years and 5 years. It allowed the tooh to be preserved in the arch, with normal function.
}

Keywords: Regenerative Endodontics; Tooth Injuries; Prognosis; Wound Healing; Cone- Beam Computed Tomography. 


\section{Resumen}

La fractura radicular puede ser definida como aquella que envuelve la dentina, cemento, ligamiento periodontal y pulpa, comprendiendo de 1,2 a 7\% de los traumas en la dentición permanente. Afecta normalmente la región de los dientes anteriores, y generalmente se cicatriza espontáneamente, dependiendo de la vitalidad pulpar. El diagnóstico es realizado a través del examen clínico, test de sensibilidad pulpar y examen radiográfico. Mas allá de esto, la Tomografía computarizada de haz cónico ha sido utilizada de forma auxiliar en el diagnóstico y pronostico debido a la reproducción de imágenes tridimensionales, permitiendo visualizar de forma exacta la localización y trayecto de la línea de fractura. Este estudio relata un caso clínico de trauma dental causado por caída de la propia altura. La paciente presentaba fractura radicular horizontal en el elemento 21, que fue confirmada a partir del examen radiográfico. La fractura estaba localizada al final del tercio medio. Como tratamiento inmediato, fue realizado el posicionamiento y entablillado. Para la confirmación de la localización exacta de la fractura y si hubo proceso de cicatrización, fueron realizadas imágenes de tomografía computarizada de haz cónico después de 30 días del trauma, y se puede visualizar la fractura con trayecto oblicuo cicatrizada por tejido calcificado. De esa forma, se optó por el seguimiento de la fractura radicular horizontal con tiempo de control de 15 días, 30 días, 60 días, 2 años y 5 años. Permitiendo así, que el diente sea preservado en la cavidad bucal sin intervenciones.

Palabras clave: Endodoncia Regenerativa; Traumatismo de los Dientes; Pronostico; Cicatrización; Tomografía Computarizada de Haz Cónico.

\section{Introdução}

As Fraturas Radiculares Horizontais (FRH) resultam, geralmente, de um impacto frontal decorrente de traumas por objeto duro ou luta. Abrangendo de 1,2 -7\% de todas as lesões traumáticas, essas, ocorrem em dentes permanentes (Andreasen, Andreasen \& Tsilingaridis, 2018; Andreasen, 1979) e afetam, normalmente, um único elemento, conforme elucidado no trabalho de Andreasen, Andreasen e Cvek (2007).

Os incisivos centrais superiores são acometidos com mais frequência, seguido dos incisivos laterais superiores e apenas em 5\% dos casos em incisivos inferiores (Andreasen, Andreasen \& Bayer, 1989).

Tradicionalmente, as fraturas radiculares horizontais eram diagnosticadas apenas por imagens radiográficas e classificadas de acordo com a posição da linha de fratura, podendo estar localizada no terço apical, médio ou cervical (Caliskan \& Pehlivan, 1996; Wolner-Hansen, 2010). Pode-se, ainda, ser definida como oblíqua, quando envolve o terço cervical e médio, ou transversal, quando se restringe apenas a um terço do dente (Cvek, Andreasen \& Borum, 2001).

Diante da necessidade de um melhor diagnóstico por imagem, as técnicas radiográficas alcançaram grandes desenvolvimentos, sendo atualmente representadas por imagens tridimensionais (Costa et al., 2014).

A Tomografia Computadorizada do tipo Cone-Beam (TCCB) tem sido utilizada com sucesso no diagnóstico e prognóstico de imagem das fraturas radiculares e se mostra superior a outros métodos radiográficos (Fagundes, Mendonça, Albuquerque \& Jacinto, 2014).

Foram realizados estudos comparando a tomografia computadorizada (TC) e radiografias para o diagnóstico de fraturas radiculares e foi demonstrado que o nível da linha de fratura em radiografias pode variar significativamente em relação à imagem tridimensional. Sendo assim, quando a exata posição da fratura horizontal não puder ser determinada, o diagnóstico radiográfico deve ser complementado com a imagem tridimensional, o que poderá afetar o planejamento do tratamento (Bornstein, Wolner- Hanssen, Sendi \& Arx, 2009; Bernardes et.al, 2009).

Com isso, houve uma melhora significativa no diagnóstico de fraturas radiculares horizontais, com relação a presença e ausência dessas, a exata localização, extensão e direção da linha de fratura (Lenzi \& Trope, 2012; Costa et al., 2011).

Fraturas radiculares geralmente apresentam um bom prognóstico, sendo caracterizada por uma comunicação entre os tecidos pulpares e periodontais, formando, assim, uma linha de fratura. Esse processo promove o reestabelecimento de uma circulação colateral e drena o edema causado pelo trauma, assim como ocorre a diminuição da tensão nos vasos pulpares (Mata, Gross \& Koren, 1985). A vitalidade pulpar normalmente é mantida após fratura radicular, ocasionando cicatrização espontânea de 70 a 80\% dos casos (Andreasen, \& Andersson, 2007; Camp, 2000). 
O reparo das fraturas radiculares horizontais envolve a união entre os segmentos por tecidos duros, calcificados (ocorre raramente), interposição de tecido conjuntivo (ocorre comumente), interposição de tecido ósseo e conjuntivo ou interposição de tecido de granulação (Neeraj, Kundabala \& Acharaya, 2011).

A separação entre os fragmentos é uma variável importante na cicatrização da fratura (Ozbek, Serper \&Semra, 2003). Se o deslocamento do fragmento coronário não for severo, ocorrerá um dano mínimo a polpa e ao periodonto. Na presença de um espaço entre os fragmentos, o reposicionamento dos mesmos aumenta a frequência de cicatrização, particularmente em dentes com formação radicular completa. Em dentes com formação radicular incompleta, uma regeneração tecidual irá ocorrer, mesmo se o espaço da fratura for persistente, pois há uma excelente capacidade pulpar de revascularização (Andrade, Campos Sobrinho, Andrade \& Matos, 2008).

A ocorrência da cicatrização continua a ser a mesma, independentemente do local da fratura em relação ao sulco gengival (Cvek, Mejare \& Andreasen, 2002). No entanto, no caso de uma invasão bacteriana proveniente do sulco gengival, a fratura na região cervical está mais propensa à contaminação devido a sua proximidade com o sulco.

O reparo da fratura por tecido duro é menos frequente no terço cervical que em outras partes da raiz, provavelmente devido a maior mobilidade do fragmento coronário (Cvek et al., 2001; Cvek et al., 2002). Além disso, o prognóstico é significativamente melhor nas fraturas oblíquas localizadas na cervical que as fraturas transversais localizadas nesta mesma região (Cvek et al., 2002), considerando que nas fraturas oblíquas, o envolvimento do terço médio ajuda a estabilizar o fragmento coronário (Fagundes et al., 2014).

Com relação ao tratamento, é proposto que haja uma redução da fratura, que consiste no alinhamento e justaposição entre os fragmentos, com estabilização do fragmento coronário com auxílio de esplintagem. Esse procedimento visa permitir a formação de uma ponte de tecido calcificado entre os fragmentos (Cvek et al., 2001). É recomendável a esplintagem do dente utilizando de uma fixação flexível por 4 semanas, se a fratura for localizada no terço médio ou apical. Se a fratura estiver localizada cervicalmente, a esplintagem permanece por um período de tempo maior (até 4 meses) (Bourguignon et al., 2020; Cvek et al., 2001; Diangelis, Andreasen \& Ebeleseder, 2012).

Torna-se de grande relevância o embasamento teórico frente ao caso clínico tratado nesse trabalho, para que o acréscimo de conhecimento possa auxiliar a prática clínica diária, frente a situações de urgência odontológica de pacientes traumatizados, em específico da FRH em dentes permanentes. Como resultado da teoria em concomitância com a prática, obteremos diagnósticos mais precisos, tratamentos adequados e prognóstico o mais positivo possível. Sendo assim, é de suma importância a compreensão acerca dos mecanismos que levam a este tipo de fratura, às respostas teciduais, bem como o manejo dos diferentes tipos de fratura e os respectivos prognósticos (Abott, 2019). O presente trabalho tem como propósito relatar um caso clínico de Cicatrização Espontânea da Fratura Radicular Horizontal (FRH) e discorrer sobre seus achados clínicos, radiográficos e tomográficos; diagnóstico, tratamento e prognóstico.

\section{Metodologia}

Para o desenvolvimento deste trabalho, foi selecionado um caso clínico de cicatrização espontânea de fratura radicular horizontal, localizado no elemento 21. O maior número de informações possíveis foi coletado através da anamnese, como a história do trauma (tipo de impacto), data, local, conduta tomada pelo acidentado/responsável, conduta emergencial tomada pelo profissional Cirurgião-Dentista que o atendeu e exames complementares solicitados. Foi realizado um termo de consentimento livre e esclarecido, para que o paciente tomasse ciência de como seria conduzido seu caso, bem como os riscos que envolvem este tipo de trauma. E dispõe de uma cláusula sobre a possível inclusão do caso em artigo científico, resguardando sua identidade e seguindo os princípios éticos. 
No exame clínico, foi executado o teste de palpação, percussão horizontal e vertical, teste de mobilidade e sensibilidade, sendo todos os dados coletados e organizados em tabelas. No exame radiográfico, para avaliação do tipo de fratura e sua localização, foi realizado o exame do tipo periapical com posicionador e o exame oclusal modificado (feixe de raio X posicionado a 90 graus da película radiográfica). Após isto, o elemento foi reposicionado com manobra digital, e posteriormente confeccionado esplintagem semirrigida de resina composta fotopolimerizável, abrangendo os elementos 12, 11, 21 e 22, para contenção do elemento 21, favorecendo assim, a cicatrização do mesmo.

Em busca de uma maior abrangência de detalhes, foi realizada uma Tomografia Computadorizada do tipo Cone-Beam (TCCB), através de seleção e associação de pontos em planos diferentes (sagital e axial), para assim obter um diagnóstico acurado, bem como estabelecer o prognóstico de maneira mais assertiva, através da localização da linha de fratura.

Concomitante ao relato do caso clínico, um levantamento bibliográfico na plataforma Pubmed, nos periódicos Dental Traumatology, Journal of Endodontics, Australian Dental Journal Supplement, Brazilian Oral Research, foi realizado, no qual os seguintes unitermos foram correlacionados: Horizontal Root fracture, Root Fracture, spountaneous healing, treatment, prognosis, diagnosis. Inicialmente, foram escolhidos 32 artigos, publicados entre 2001 e 2020. Após análise dos critérios de inclusão (acesso ao artigo completo via internet e possuir relação direta com o objetivo do trabalho), 25 artigos foram selecionados, comparados entre si, assim como ao caso clínico do presente trabalho, através de seus achados clínicos, radiográficos e tomográficos. Somado aos artigos específicos, alguns autores fornecem suporte metodológicos: Estrela, C. (2018). Metodologia Científica: Ciência, Ensino, Pesquisa. Editora Artes Médicas; Pereira A. S. et al. (2018). Metodologia da pesquisa científica. [free e-book]. Santa Maria/RS. Ed. UAB/NTE/UFSM ; Koche, J. C. (2011). Fundamentos de metodologia científica. Petrópolis: Vozes. Disponível; Ludke, M. \& Andre, M. E . D. A. (2013). Pesquisas em educação: uma abordagem qualitativa. São Paulo: E.P.U. Yin, R.K. (2015). O estudo de caso. Porto Alegre: Bookman.

\section{Relato de Caso}

Em fevereiro de 2016, paciente E.A, do sexo feminino,14 anos, leucoderma, procurou acompanhada de responsável, o Centro de Especialidades Odontológicas do Município de Campo Alegre no estado de Alagoas, com histórico de queda da própria altura e impacto frontal da boca em uma pedra, trauma esse ocorrido no mesmo dia do atendimento clínico. Posteriormente, a paciente foi encaminhada para Associação Brasileira de Odontologia de Alagoas no município de Maceió para realização de acompanhamento e demais condutas para o caso.

No dia do primeiro atendimento clinico, observou-se ferimento corto-contuso em lábio inferior (Figura 1), e elemento dental 21 ligeiramente extruido e vestibularizado (Figura 2) com discreto sangramento no sulco gengival, além de apresentar mobilidade moderada. Os ferimentos foram desinfetados com soro fisiológico e solução de digluconato de clorexidina a $0,12 \%$ (Periogard - Colgate ${ }^{\circledR}$ ). Apresentou estado de higiene bucal considerado bom, favorecendo o prognóstico do caso. 
Figura 1 - Aspecto lábio inferior.

Figura 2 - Aspecto do elemento dental 21.

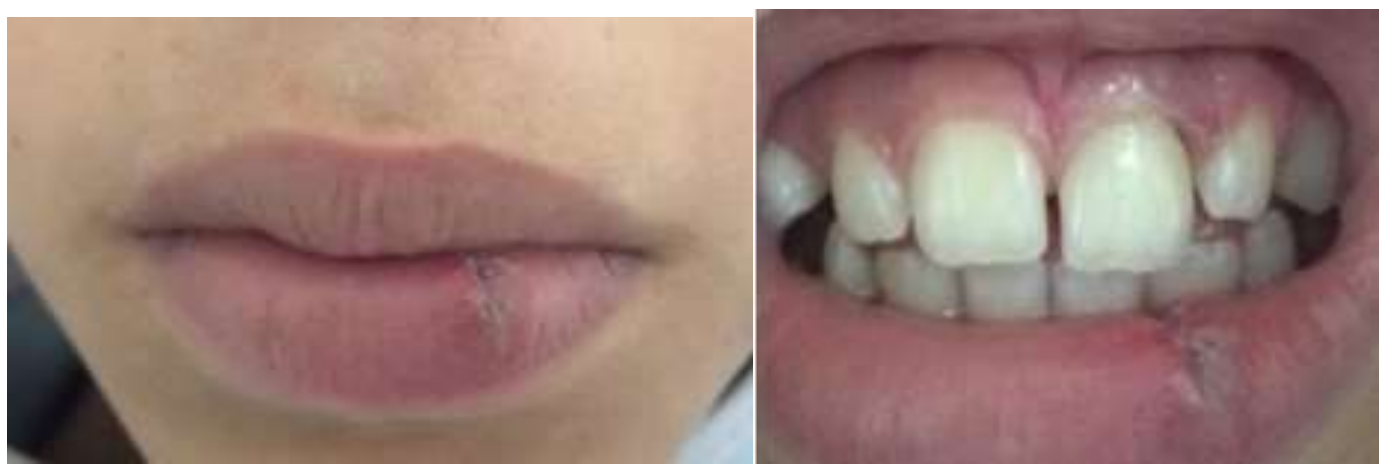

Fonte: Autoria própria.

O teste de sensibilidade ao frio com gás refrigerante foi realizado a fim de averiguar sensibilidade pulpar, e avaliar a vitalidade pulpar, porém o dente respondeu negativamente ao teste no primeiro momento.

Foram realizadas tomadas radiográficas periapical e oclusal modificada, em que pôde-se verificar através da imagem a presença de Fratura Radicular Horizontal (FRH) transversal no terço médio do elemento 21 na radiografia periapical (figura 3) e na radiografia oclusal modificada (figura 4).

Figura 1 - Radiografia periapical.

Figura 4 - Radiografia oclusal modificada.
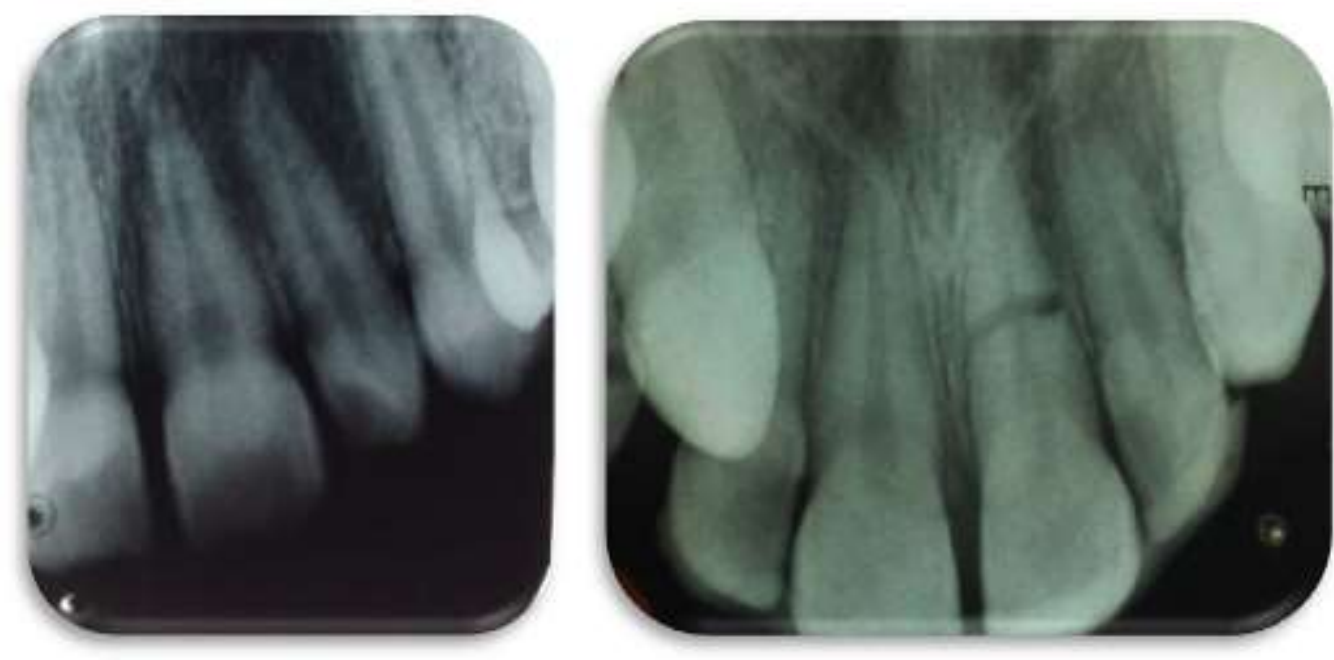

Fonte: Autoria própria.

Com a obtenção do diagnóstico de Fratura Radicular Horizontal, foi realizado o reposicionamento do fragmento, mediante anestesia infiltrativa. Após isso, foi realizado o reposicionamento do fragmento coronário, e posterior tomada radiográfica para a confirmação de uma boa justaposição dos fragmentos. Com a confirmação, foi realizada uma contenção semirrígida com resina composta, a fim de manter o fragmento em posição e permitir seu reparo (Figura 5). Após a instalação da contenção, mais uma tomada radiográfica foi realizada no intuito de avaliar o reposicionamento dental e a radiografia periapical (figura 6) mostrou o correto posicionamento dos dois fragmentos. 
Figura 2 - Esplintagem.

Figura 3 - Radiografia periapical.

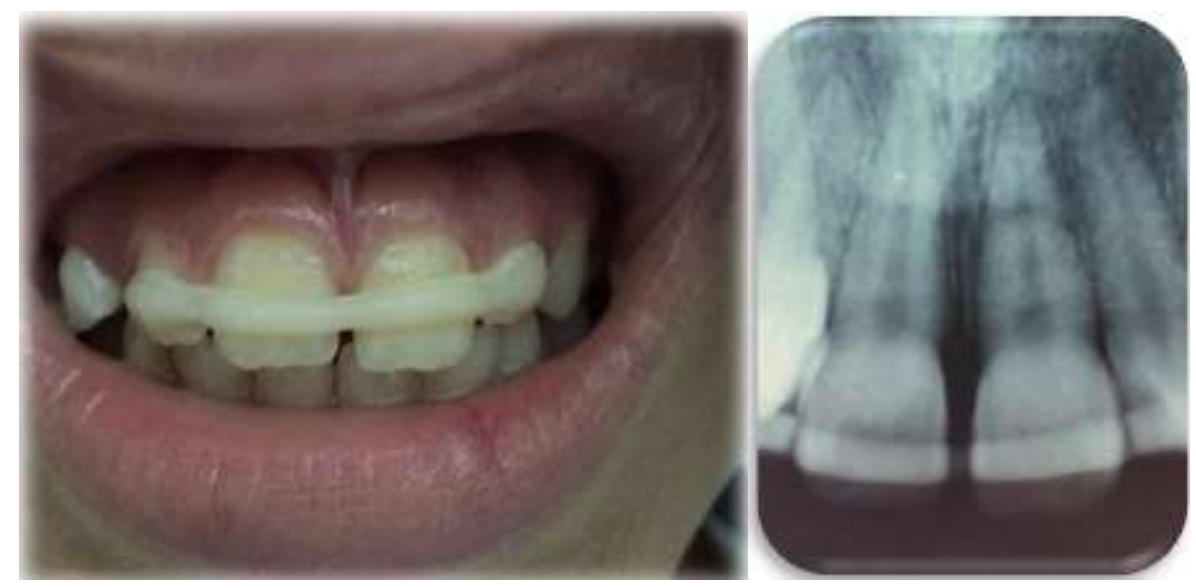

Fonte: Autoria própria.

Após 15 dias ao atendimento de urgência, foram realizadas novas tomadas radiográficas periapical e oclusal, nas quais não foram observadas alterações. $O$ teste de sensibilidade pulpar ao frio foi realizado e o elemento dental respondeu positivamente. $\mathrm{O}$ fragmento coronário ainda apresentava certa mobilidade, o que levou à tomada de decisão de manutenção da esplintagem por mais 2 semanas. Após 30 dias, a paciente foi novamente avaliada, e neste momento, foi realizado o teste de sensibilidade pulpar ao frio, que respondeu positivamente. $\mathrm{O}$ elemento dental ainda apresentava uma leve mobilidade, o que levou a decisão por manutenção da esplintagem. Neste mesmo dia, a paciente foi encaminhada para Clínica Radiológica para a realização de Tomografia Computadorizada do tipo Cone-Beam da maxila.

As imagens foram realizadas com o objetivo de: (a) melhor visualização da extensão da fratura, (b) identificar a localização da fratura, (c) avaliar reposicionamento do fragmento coronário com relação ao fragmento apical, (d) identificar o tipo de reparo da linha de fratura e (e) identificar possíveis pontos de reabsorção.

As imagens tomográficas (Figura 7) confirmaram a FRH do elemento 21, porém, quanto a extensão da fratura (a), pôde ser identificado o aspecto oblíquo da fratura e não transversal conforme visto nas imagens radiográficas periapical e oclusal.

Quanto à localização da linha de fratura (b) sendo do tipo oblíquo, apresentava-se no terço médio na face vestibular da raiz, e no terço cervical, a cerca de $2 \mathrm{~mm}$ da linha amelo-dentinária no que diz respeito a face palatina da raiz, podendo influenciar no prognóstico do caso.

O reposicionamento (c) no momento da urgência traumatológica pôde ser considerado eficaz, já que os dois fragmentos se mostraram bem justapostos. O que influenciou no tipo de reparo identificado (d), cicatrização por tecido calcificado. Não foi observado sinal de reabsorção (e).

Decorridos 60 dias, a paciente retornou para avaliação. Novas tomadas radiográficas periapical e oclusal modificada foram realizadas, mostrando nenhuma alteração de imagem, e o elemento dental foi mais uma vez submetido ao teste de sensibilidade com frio, respondendo positivamente. Com o fragmento coronário apresentando mobilidade considerada fisiológica, sendo assim, decorridas 8 semanas, a esplintagem foi removida. 
Research, Society and Development, v. 10, n. 12, e59101219988, 2021

(CC BY 4.0) | ISSN 2525-3409 | DOI: http://dx.doi.org/10.33448/rsd-v10i12.19988

Figura 7 - Imagens tomográficas.
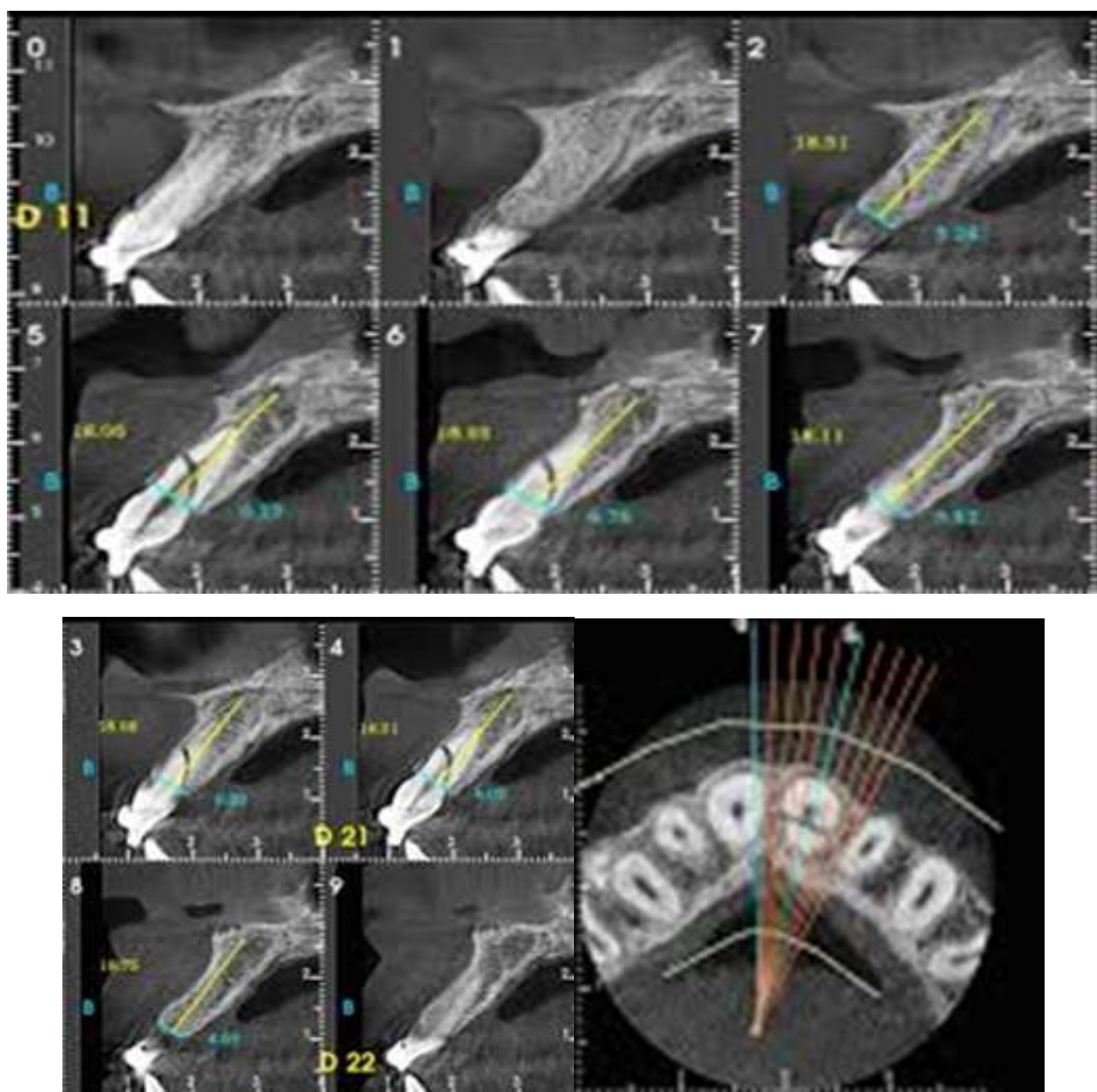

Fonte: Autoria própria.

Após 2 anos, paciente retornou para o acompanhamento e foi realizado teste de sensibilidade ao frio, respondendo positivamente, bem como exame radiográfico (figura 8), com aspecto favorável de cicatrização, porém, com alguns pontos de reabsorção.

Figura 8 - Radiografia oclusal modificada- 2 anos.

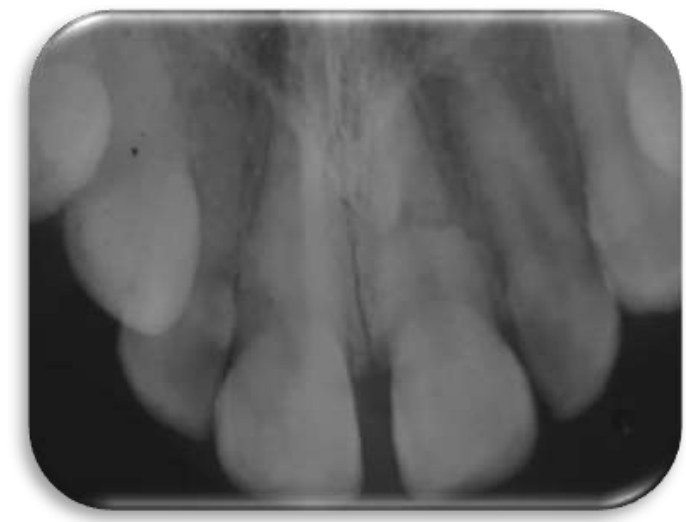

Fonte: Autoria própria. 
Com 5 anos de acompanhamento, paciente mudou de cidade, e em sua nova morada, procurou um dentista e optou pela realização de tratamento ortodôntico para fins estéticos. Foi realizada uma nova radiografia periapical (figura 9), em que não houveram mudanças significativas de imagem quando comparado a dois anos de acompanhamento.

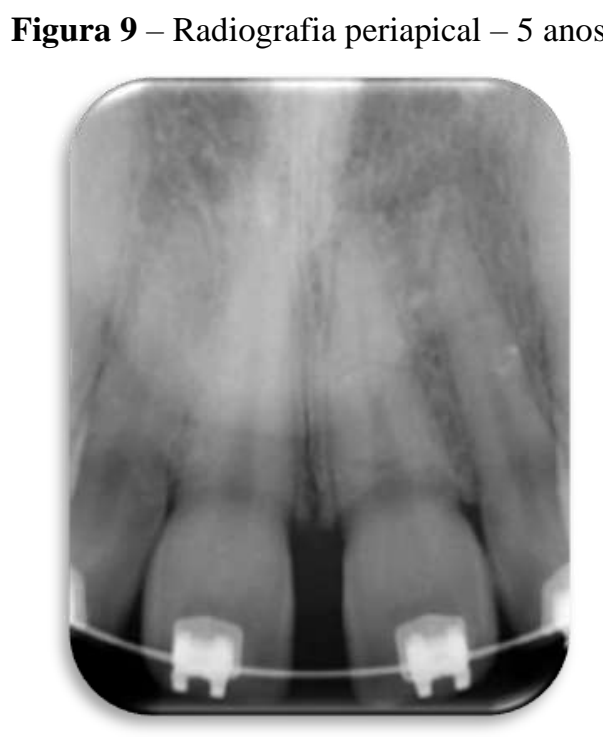

Fonte: Autoria própria.

\section{Discussão}

Diante da suspeita de fratura radicular horizontal, uma avaliação clínica abrangente deve ser realizada, a fim de reunir o maior número de informações com relação ao trauma.

Neste relato de caso pudemos verificar a presença inicial de uma suspeita de fratura radicular horizontal, em que a partir da avaliação clínica compreendida pelo relato da paciente, analisou-se a mobilidade do elemento, dor a palpação nos tecidos moles, sangramento do sulco gengival, percussão do dente afetado, teste de sensibilidade e exame radiográfico; pôde-se diagnosticar a fratura radicular horizontal.

Com relação aos sinais clínicos, Andreasen e Andreasen (2001) relataram que é possível visualizar extrusão ou aspecto normal do fragmento coronário, sensibilidade à palpação e teste de percussão. Somado a isso, pode haver a presença de sangramento no sulco gengival, indicando trauma na região de ligamento periodontal ou outros tecidos, conforme elucidado por Flores et al. (2007). Esses mesmos sinais clínicos citados foram encontrados no caso do presente trabalho, sendo possível visualizar o sangramento no sulco gengival, extrusão do fragmento coronário e dor à palpação, além da mobilidade do fragmento.

Segundo Ohman (1965) e Andreasen (1986), ao realizar a avaliação da vitalidade pulpar após o trauma, essa é considerada um desafio diagnóstico importante, pois muitas vezes pode ocorrer uma perda de sensibilidade no momento inicial. Após trauma agudo, o suprimento sanguíneo da polpa é afetado, levando a um edema pulpar e consequentemente pode ocasionar uma resposta negativa após a injúria. Decorrido um período de 10 a 14 dias, pode ocorrer uma resposta pulpar positiva.

A Tabela 1 mostra os resultados do teste de sensibilidade pulpar no caso descrito em relação ao período de acompanhamento, assim como citado o trabalho de Ohman (1965) e Andreasen (1986). No presente caso, ao teste de sensibilidade obteve-se resposta negativa no primeiro momento, e respeitando o período transitório de 15 dias, respondeu 
positivamente ao teste de sensibilidade. Aos 30 dias, pôde-se confirmar a vitalidade pulpar, já que o elemento dentário traumatizado continuou com uma resposta positiva ao teste de sensibilidade ao frio, conforme demonstrado na Tabela 1.

Tabela 1 - Achados clínicos de acompanhamento (zero, 15, 30, 60 dias, 2 e 5 anos).

\begin{tabular}{|c|c}
\hline Dias & Teste de sensibilidade ao frio \\
\hline Inicial & - \\
\hline $\mathbf{1 5}$ dias & + \\
\hline $\mathbf{3 0}$ dias & + \\
\hline $\mathbf{6 0}$ dias & + \\
\hline $\mathbf{2}$ anos & + \\
\hline $\mathbf{5}$ anos & + \\
\hline
\end{tabular}

Fonte: Autoria própria.

Portanto, a resposta negativa no primeiro momento após a injúria não é sinal de necrose pulpar e não é indicativo para a realização de tratamento endodôntico.

Após a avaliação clínica, é de suma importância à realização do exame radiográfico, para confirmação da hipótese diagnóstica, e assim, para poder avaliar a localização e extensão da fratura, se simples ou múltipla. A imagem radiográfica depende do ângulo da fratura e a incidência do raio-x, e a combinação desses dois fatores pode melhorar ou esconder a linha da fratura, conforme elucidado por Soares e Goldberg (2001). Sendo assim, se o feixe de raio-x não passar diretamente pela linha de fratura, essa pode não ser vista radiograficamente. Com isso, devemos realizar incidências em diferentes angulações. Segundo Bourguignon et al. (2020), é ideal a realização de tomadas radiográficas ortorradiais, mesioanguladas e oclusais, para uma melhor visualização da linha de fratura

No caso em questão, foram realizadas radiografias do tipo ortorradial e oclusal modificada. As tomadas radiográficas em diferentes angulações e utilizando uma técnica diferente, são importantes para que haja uma confirmação da fratura, da sua extensão e localização aproximada, para que se possa realizar um bom diagnóstico e para uma correta condução do caso. Quando temos conhecimento das variações que ocorrem ao realizar a radiografia, utilizamos desses recursos para que seja feito o diagnóstico de forma mais precisa. No caso em questão, apesar da radiografia ortorradial indicar a fratura radicular horizontal ao final do terço médio, realizou-se a oclusal modificada para uma maior precisão, sendo que em ambas pôde-se observar a fratura no mesmo nível.

Em 2009, Likubo et al. observaram limitações nas radiografias periapicais para a detecção de fraturas. Foram vistas desvantagens inerentes aos métodos radiográficos convencionais, tais como: magnificação, distorção e sobreposição anatômica de imagens bidimensionais. Cohenca, Simon, Roges, Morag e Malfaz (2007) também relataram uma pobre sensibilidade da radiografia convencional para a detecção de pequenos deslocamentos do fragmento, assim como a fratura alveolar. As limitações são devidas a projeção geométrica, sobreposição de estruturas anatômicas e erros no processamento. Porém, continua sendo a opção mais viável, no que se diz respeito ao fácil acesso dos profissionais.

Segundo Caliskan e Pehlivan (1996) e Wolner -Hanssen (2010), as fraturas horizontais são classificadas de acordo com a localização da linha de fratura, em que podem se localizar no terço cervical, médio e apical. Além disso, pode ser definida como oblíqua, quando envolve o terço cervical e médio; ou transversal, quando se restringe a um só terço da raiz, 
como relatado por Cvek et al. (2002). Radiograficamente, foi possível visualizar a localização da fratura no caso relatado, ao final do terço médio, com aparente trajeto transversal, quando analisados através da radiografia intraoral.

A partir de uma avaliação realizada por Çaliskan e Pehlivan, em 1996, em 56 fraturas radiculares, mostrou-se que as fraturas em terço médio foram as mais comuns, equivalente a 57\% dos casos, seguida do terço apical em $34 \%$ e cervical, em $9 \%$ dos casos.

Como demonstrado no trabalho de Feiglin (1995), o prognóstico da fratura localizada no terço cervical, pode ser considerado pobre devido a mobilidade do fragmento coronário, além da possível contaminação bacteriana originada do sulco gengival. Sendo assim, para um melhor prognóstico, devemos orientar o paciente para um cuidado maior com a higienização bucal, a fim de tentar reduzir a carga bacteriana.

Quando analisamos o caso exposto, ao observar apenas a radiografia intraoral, podemos concluir que o prognóstico é mais favorável quando comparado ao terço cervical, conforme elucidado por Feiglin (1995), pois se encontraria distante do sulco gengival, sendo menor a possibilidade de contaminação proveniente do sulco gengival. Porém, clinicamente, o fragmento coronário apresentava uma mobilidade mais acentuada, havendo um questionamento quanto a real localização da linha de fratura, se envolvia ou não o terço cervical em um possível trajeto oblíquo. Assim, optou-se pela realização de imagens tomográficas para complementação do diagnóstico.

Segundo Bornstein et al. (2009) e Bernardes et al. (2009), quando se trata de localização de linha de fratura, imagens provenientes da tomografia computadorizada (tridimensional) podem mostrar uma localização diferente quando comparadas às radiografias periapicais. Sendo assim, quando a posição exata da fratura radicular horizontal não for determinada através de radiografia, esta deve ser complementada com a imagem tridimensional. A tomografia computadorizada do tipo cone-beam ajuda a determinar a localização, extensão e direção de uma fratura, conforme elucidado por Bourguignon et al. (2020). Podendo, assim, afetar o plano de tratamento.

Em contrapartida, como demonstrado no Quadro 1, podemos ver a comparação entre a localização radiográfica e tomográfica do caso em questão, mostrando que a imagem radiográfica não localiza a posição da fratura, pois a radiografia possui uma perspectiva diferente quando comparada à tomografia; sendo uma bidimensional e outra tridimensional, respectivamente. Ou seja, o nível da linha da fratura não pode ser determinado pela radiografia. Em que, inicialmente, através da imagem radiográfica, a fratura estava localizada ao final do terço médio com trajeto transversal, e com a realização da tomografia, visualizamos a fratura com trajeto oblíquo partindo do final do terço médio na face vestibular e até o terço coronário na face lingual.

Dessa forma, o prognóstico é alterado, passando de favorável a duvidoso devido ao seu trajeto, reafirmando o trabalho de Feiglin (1995), em que quando a localização encontra-se no terço cervical, a mobilidade e a possibilidade de contaminação bacteriana levam a um pior prognóstico. 
Quadro 1 - Comparação entre achados radiográficos e tomográficos quanto à localização da fratura radicular e o prognóstico da lesão.

\begin{tabular}{l|l|l}
\hline & Radiográfico Intraoral & Tomográficos \\
\hline Localização da fratura & Final do terço médio & Face vestibular - Final do terço médio; \\
& & Face palatina - Terço cervical \\
\hline Prognóstico & Favorável & Duvidoso \\
\hline
\end{tabular}

Fonte: Autoria própria.

Com relação ao reposicionamento após a identificação da fratura radicular horizontal, artigos publicados demonstraram que se houver um deslocamento do fragmento coronário, o reposicionamento está relacionado significativamente a formação de tecido duro, conforme estudo realizado por Cvek et al. (2001) e Cvek et al. (2002).

Em 2001, Cvek et al. afirmaram que, fatores como o tipo de esplintagem (rígida ou semirrígida), o tipo de fratura e o tratamento tardio, não afetam significativamente a frequência e o tipo de cicatrização. Já em 2020, Bourguignon et al. elaboraram o Guia Internacional de Traumatologia Dental para o manejo de injúrias traumáticas dentárias, em que sugerem a confecção de esplintagem semirrígida, variando de um período de 4 semanas, e se a fratura estiver próxima ao terço cervical, a estabilização torna-se benéfica por um período mais longo, de aproximadamente 4 meses. Estudos anteriores mostraram que a esplintagem dos fragmentos coronários e a duração dessa em casos de fraturas localizadas no terço médio e apical, tiveram pouca relevância, enquanto fatores como estágio de desenvolvimento radicular, sensibilidade pulpar e reposicionamento de fragmentos deslocados, foram altamente preditivos quanto a frequência e tipo de cicatrização, conforme afirmado por Cvek et al. (2001).

No caso clínico exposto neste trabalho, optou-se pelo reposicionamento, visto que o fragmento coronário encontravase ligeiramente extruído e vestibularizado, visando também a redução da diástase entre fragmentos, para uma melhor cicatrização e formação de tecido duro; visto que, com a redução da fratura, o risco de invasão bacteriana cai devido a uma diminuição do coágulo, sendo esse um bom substrato para crescimento bacteriano, conforme elucidado por Andreasen, Andreasen, Mejare e Cvek. (2004).

Com relação à esplintagem, foi confeccionada seguindo os padrões do Guia Internacional de Traumatologia Dental (contenção semirrígida), porém foi mantida por um período de 2 meses, devido a mobilidade do fragmento, que ainda não se apresentava de forma fisiológica. Além disso, instruções com relação a higiene bucal foram reforçadas e acompanhadas no período de proservação

A cicatrização da fratura radicular horizontal pode ser classificada em 4 grupos, de acordo com Andreasen, Andreasen e Tsilingaridis (2018): 1. Cicatrização com tecido duro (é a cicatrização ideal, ocorre quando há um deslocamento mínimo dos fragmentos coronários, quando não há deslocamento dos mesmos ou quando houve um deslocamento significativo, porém, reposicionado rapidamente); 2. Cicatrização por interposição de tecido conjuntivo (é a resposta mais provável para fraturas com deslocamento do fragmento coronário, em que que não há união dos fragmentos fraturados, porém, ocorre uma estabilização do mesmo); 3. Interposição de tecido conjuntivo e tecido duro (esta resposta ocorre principalmente em pacientes jovens, em dentes permanentes imaturos); 4. Não houve reparo (presença ou espaço alargado entre os fragmentos e a presença de radiolucidez no osso alveolar adjacente a fratura, devido a necrose pulpar no fragmento coronário). Esta classificação foi confirmada em estudos pregressos, como os de Andreasen e Hjorting-Hansen (1967), Lindahl (1963), Cvek, Andreasen e Borum (2001). 
Com relação à cicatrização, Oztan e Sonat (2001) afirmaram que é iniciada na polpa e no ligamento periodontal, agindo de forma competitiva. Na ausência de infecção, a resposta pulpar pode seguir dois caminhos a depender da integridade do tecido pulpar. Se permanecer intacto, a resposta é essencialmente similar a exposição pulpar coronária, ocorre a formação de uma barreira de tecido duro unindo os dois fragmentos. Se a polpa lacerar, a cicatrização desta ocorre por meio de um processo de revascularização, podendo resultar na calcificação do espaço pulpar coronário.

No caso do presente trabalho, a partir do reposicionamento e posterior esplintagem, os fragmentos mantiveram-se mais justapostos, contribuindo para uma cicatrização espontânea por tecido calcificado.

A proservação a longo prazo dos pacientes que sofreram trauma é de extrema importância para que se possa avaliar as possíveis mudanças patológicas que podem ocorrer no passar dos anos. Assim, a cicatrização da fratura de forma espontânea, sem a realização de tratamento endodôntico é relatada em diversos artigos, conforme observado no estudo de Fagundes et al. (2014). Como ilustrado no caso relatado, a polpa pode permanecer vital, com ausência de patologia. Porém, se for observado durante a proservação, uma resposta de sensibilidade pulpar negativa após o período transitório (10-14 dias) ou radiograficamente com a presença de lesão no fragmento coronário, indicando necrose pulpar, sendo assim, o tratamento endodôntico deve ser realizado, conforme elucidado por Oztan e Sonat (2001).

A respeito da proservação, o Guia Internacional de Traumatologia Dental (2020) propôs o acompanhamento no período de 30 dias, 45 a 60 dias, 4 meses, 6 meses, um ano e 5 anos, devendo ser realizado exames clínicos e radiográficos, para avaliar cada caso. No presente trabalho, pudemos observar que houve a preservação iniciando após 15 dias do trauma, para avaliar a sensibilidade do fragmento, devido ao período transitório.

Tabela 2 - Achados clínicos e radiográficos de acompanhamento (zero, 15, 30, 60 dias, 2 e 5 anos).

\begin{tabular}{|c|c|c|c|}
\hline & $\begin{array}{c}\text { Teste de } \\
\text { sensibilidade ao } \\
\text { frio }\end{array}$ & Radiografia Intraoral $^{1}$ & Mobilidade $^{2}$ \\
\hline Inicial & - & Linha de fratura, sem sinais de reabsorção & Grau 2 \\
\hline 15 dias & + & Fratura reduzida, sem sinais de reabsorção & Grau 2 \\
\hline 30 dias & + & Fratura reduzida, sem sinais de reabsorção & Grau 1 \\
\hline 60 dias & + & Fratura reduzida, sem sinais de reabsorção & Fisiológica \\
\hline 2 anos & + & Fratura reduzida, com sinais de reabsorção & Ausência de mobilidade \\
\hline 5 anos & + & Fratura reduzida, com sinais de reabsorções & Ausência de mobilidade \\
\hline
\end{tabular}

Conforme descrito na Tabela 2, pode-se verificar que no teste de sensibilidade inicial, houve uma resposta negativa devido ao edema pulpar, e radiograficamente visualizava-se a linha de fratura, não reduzida e sem sinais de reabsorção nos bordos da mesma. Já após 15 dias, o dente respondeu positivamente, as imagens radiográficas apresentavam-se com uma fratura reduzida e sem sinais de reabsorção. Este padrão continuou após 30 e 60 dias, diferindo apenas na questão da mobilidade, em que no período de 30 dias houve uma diminuição e com 60, a mobilidade encontrava-se fisiológica. Passados 2 anos, observou-se a ausência de mobilidade e o mesmo padrão se repetiu aos 5 anos. 


\section{Considerações finais}

A polpa pode permanecer vital em dentes com fratura radicular horizontal, e a região entre os fragmentos, pode cicatrizar espontaneamente, sem alterações patológicas. É de extrema importância o conhecimento acerca do diagnóstico e dos recursos que se pode utilizar para uma correta localização da fratura, e assim, traçar um plano de tratamento correto, buscando a manutenção da vitalidade pulpar, e não a intervenção endodôntica precipitada. O período de 10 a 14 dias de resposta transitória ao teste de sensibilidade deve ser considerado em todos os casos, e o teste precisa ser realizado novamente após esse tempo, a fim de um correto diagnóstico de vitalidade ou necrose pulpar. O sucesso do tratamento será indicado durante o período de proservação, buscando sempre a realização do exame clínico e radiográfico de acompanhamento no período de 30 dias, 45 a 60 dias, 4 meses, 6 meses, um ano e 5 anos.

Novos estudos clínicos e laboratoriais podem ser realizados a fim de avaliar a localização da fratura radicular horizontal através da análise por TCCB, comparada a imagem do mesmo dente por radiografia periapical, avaliando se a localização em ambos os casos são condizentes e a influência dessa comparação no prognóstico da fratura radicular horizontal.

\section{Referências}

Abbott, P.V. (2019). Diagnosis and management of transverse root fractures. Dent Traumatol. 00, 1-15.

Andrade, E. S., Campos Sobrinho, A. L. de, Andrade, M. G. \& Matos, J. L. (2008). Root healing after horizontal fracture: a case report with a 13-year follow up. Dent Traumatology, 8 (24), e1-3.

Andreasen, F. M. (1986). Transient apical breakdown and its relation to color and sensibility changes. Endod Dent Traumatol. 2, 9-19.

Andreasen, F. M., Andreasen, J. O. \& Bayer, T. (1989). Prognosis of root-fractured permanent incisors - prediction of healing modalities. Endod Dent Traumatol. 5, 11-22.

Andreasen, F. M., Andreasen, J. O. \& Cvek, M. (2007) Root fractures. In:Andreasen, J.O.; Andreasen, F.M.; Andersson, L. editors. Textbook and color atlas of traumatic injuries to the teeth. 4th edn. Kopenhagen: Blackwell Munksgaard. 337-7.

Andreasen, F. M., Andreasen, J. O. \& Tsilingaridis, G. (2018). Root fractures. In: Andreasen JO, Andreasen FM, Andersson L, eds. Textbook and Color Atlas of Traumatic Injuries to the Teeth. 5th ed. Oxford, UK: Wiley Blackwell. 377-412.

Andreasen, J. O.(1979). Etiology and pathogenesis of traumatic dental injuries. A clinical study of 1,298 cases. Scand J Dent Res.78, 329-42.

Andreasen, J. O. \& Andreasen, F. M. (2001). Fundamentos de traumatismo dental: guia de tratamento passo-a-passo. Porto Alegre: Artmed Editora. 188.

Andreasen, J. O. \& Hjording - Hansen, E. (1967). Intra-alveolar root fractures: radiographic and histologic study of 50 cases. J Oral Surg. 25 , $414-26$.

Andreasen, J. O, Andreasen, F. M., Mejare, J. \& Cvek, M. I. (2004). Healing of 400 intra-alveolar root fractures. 1. Effect of pre-injury and injury factors such as sex, age, stage of root development, fracture type, location of fracture and severity of dislocation. Dent traumatol.20, 192-202.

Bernardes, R. A., Moraes, I. G. de, Duarte, M. A., Azevedo, B. C., Azevedo, J. R. de \& Bramante, C. M. (2009). Use of cone-beam volumetric tomography in the diagnosis of root fractures. Oral Surg Oral Med Oral Pathol Oral Radiol Endod. 108, $270-7$.

Bornstein, M. M., Wolner- Hanssen, A. B., Sendi, P. \& Arx, V. T. (2009). Comparison of intraoral radiography and limited cone beam computed tomography for the assessment of root-fractured permanent teeth. Dent Traumatol.25, 571-7.

Bourguignon, C., Cohenca, N. \& Lauridsen, E. et al. (2020). International Association of Dental Traumatology guidelines for the management of traumatic dental injuries: 1. Fractures and luxations. Dent Traumatol. 36,314-330.

Caliskan, M. K. \& Pehlivan, Y. (1996). Prognosis of root-fractured permanent incisors. Endod Dent Traumatol . 12, 129-36.

Camp, J. H. (2000). Management of sports-related root fractures. Dent Clin North Am. 44,95-109.

Cohenca, N., Simon, J. H., Roges, R., Morag, Y. \& Malfaz, J. M. (2007). Clinical indications for digital imaging in dento-alveolar trauma. Part 1: traumatic injuries. Dent Traumatol. 23(2), 95-104.

Costa, F. F., Pinheiro, L. R., Umetsubo, O. S., Santos Junior, O. de, Gaia, B. F. \& Cava, M. G. (2014). Influence of cone-beam computed tomographic scan mode for detection of horizontal root fracture. Journal of Endodontics. 40, 1472-6.

Cvek, M., Andreasen, J. O. \& Borum, M. K. (2001). Healing of 208 intraalveolar root fractures in patients aged 7-17 years. Dent Traumatol. $17,53-62$.

Cvek, M., Mejare, I. \& Andreasen, J. O. (2002). Healing and prognosis of teeth with intra-alveolar fractures involving the cervical part of the root. Dent Traumatol. 18, 57-65. 
Research, Society and Development, v. 10, n. 12, e59101219988, 2021

(CC BY 4.0) | ISSN 2525-3409 | DOI: http://dx.doi.org/10.33448/rsd-v10i12.19988

Diangelis, A. J., Andreasen, J. O. \& Ebeleseder, K. A. (2012). International Association of Dental Traumatology guidelines for the management of traumatic dental injuries: 1. Fractures and luxations of permanent teeth. Dent Traumatol. 28, 2-12.

Fagundes, D., Mendonça, I., Albuquerque, T. \& Jacinto, I. (2014). Spontaneous healing responses detected by cone-beam computed tomography of horizontal root fractures: a report of two cases. Dent Traumatol. 30, 484-7.

Feiglin, B. (1995). Clinical management of transverse root fractures. Dent Clin North Am. 39, 53-78.

Flores, M. T., Andersson, L., Andreasen, J. O., Bakland, L. K., Malmgren, B. \& Barnett, F. (2007). Guidelines for the management of traumatic dental injuries.1. Fractures and luxations of permanent teeth. Dent Traumatology. 23,66-71.

Lenzi, R. \& Trope, M. (2012). Revitalization procedures in two traumatized incisors with diferente biological outcomes. J Endod. 38,411-4.

Likubo, M., Kobayashi, K., Mishma, A., Shimoda, S., Daimaruya, T. \& Igashi, C. et al. (2009). Accuracy of intraoral radiography, multidetector helical CT, and limitedcone-beam CT for the detection of horizontal root fracture. Oral Surg Oral Med Oral Pathol Oral Radiol Endod. 108, e70-4.

Lindahl, B. (1963). Transverse intra-alveolar root fractures: Roentgen diagnosis and prognosis. Odont Revy. 1963;9:10-24.

Mata, E., Gross, M. A. \& Koren, L.Z. (1985). Divergent types of repair associated with root fractures in maxillary incisors. Endod Dent Traumatology. 1,1503 .

Neeraj, M., Kundabala, M. \& Acharaya, S. (2011). A review of root fractures: diagnosis, treatment and prognosis. Dent Update. 38,615 - 628.

Ohman, A. (1965). Healing and sensitivity to pain in young replanted human teeth. An experimental, clinical and experimental study. Odontol Tidskr. 73 , 166 -227 .

Ozbek, M., Serper, A. \& Semra, Ç. (2003). Repair of untreated horizontal root fracture: a case report. Dent Traumatol. $19,296-7$.

Oztan, M. D. \& Sonat, B.( 2001). Repair of untreated horizontal root fractures: two case reports. Dent Traumatol. 17(5),240-3.

Pereira, A. J. A., Araújo, C. Y. T., Almeida, C. C. N. \& Souza, C. (1997). Conseqüência do diagnóstico equivocado no prognóstico das fraturas radiculares. Rev Assoc Paul Cir Dent. 51(6),579-582.

Soares, J. J. \& Goldberg, F. (2001). Endodontia: técnica e fundamentos. Porto Alegre: Artes Médicas Sul. 376.

Wolner-Hanssen, A. B. \& Von Arx, T. (2010). Permanent teeth with horizontal root fractures after dental trauma. A retrospective study. Schweiz Monatsschr Zahnmed. 120, 200-212. 